\title{
Modelling Biodiesel Supply Chain: Current State and Opportunities for Future Research
}

\author{
Fitriani Tupa Ronauli Silalahi ${ }^{1,2, *}$, Togar Mangihut Simatupang ${ }^{3}$, \\ Manahan Parlindungan Siallagan ${ }^{3}$, and Rizal Horas Manahan Sinaga ${ }^{4}$ \\ ${ }^{1}$ School of Business and Management, Bandung Institute of Technology, Jl. Ganesha no 10, \\ Bandung 40132, West Java, Indonesia \\ ${ }^{2}$ Faculty of Industrial Technology, Del Institute of Technology, Laguboti 22381, Toba, \\ North Sumatera, Indonesia \\ ${ }^{3}$ School of Business and Management, Bandung Institute of Technology, Jl. Ganesha no 10, \\ Bandung 40132, West Java, Indonesia \\ ${ }^{4}$ Faculty of Engineering, University of Nottingham, University Park, Nottingham, NG7 2 RD, \\ United Kingdom
}

\begin{abstract}
The use of renewable energy is an important issue that is being promoted internationally. Considering the supply of fossil energy is increasingly depleting and requires a very long time to be renewed. One of the uses of renewable energy that is being promoted is the use of biodiesel as a substitute for diesel fuel. This utilization is carried out by mixing biodiesel with diesel fuel. The quantity of biodiesel blended with diesel fuel is following the rules in each country. That is why the biodiesel supply chain must be described to obtain minimum economic costs and environmental costs. This paper presents a comprehensive review of current biodiesel supply chain models. A study of the biodiesel supply chain's current state concludes by highlighting the unaddressed area or the gaps existing in the existing literature by suggesting future research in the biodiesel supply chain, specifically in the area case study in Indonesia.
\end{abstract}

Keywords: Biodiesel energy, environmental impact, systematic literature review, renewable energy, research gaps.

\section{Introduction}

Over the last decade, research on renewable energy use is increasingly carried out to reduce dependence on fossil energy and develop renewable and environmentally friendly energy sources. Unfortunately, humans still rely heavily on non-renewable energy sources. Until the end of 2017, the use of renewable energy globally is estimated at $26.5 \%$. This consumption increased by $5 \%$ compared to renewable energy consumption in 2016 by $20.5 \%$ (Figure 1) [1]. The use of renewable energy is still very little compared to the fossil energy that feared to run out. This dependency on traditional sources is causing adverse effects on human health and the environment due to global deforestation and greenhouse emissions [2].

*Corresponding author: fitriani_tupa@sbm-itb.ac.id 
Renewable energy resources can be classified into two types: i) static renewable energy and ii) biofuels. Static resources like wind, solar, geothermal heat, tides, and waves should be consumed just after generation. In contrast, biofuels can be transported in order to use in far districts for consumption. At the same time, biofuels have shown a great potential to be a promising alternative for fluid fossil fuel consumption and can reduce both fossil fuel dependency and greenhouse gas (GHG) emissions. Currently, biofuel is divided into bioethanol and biodiesel. Biodiesel is a fuel with low viscosity, non-toxic, biodegradable, and cleaner than fossil diesel. There are more than 350 oil-bearing crops known in the world that are suitable for biodiesel production [3].

Global Trends in Ethanol, Biodiesel and HVO/HEFA Production, 2007 to 2017

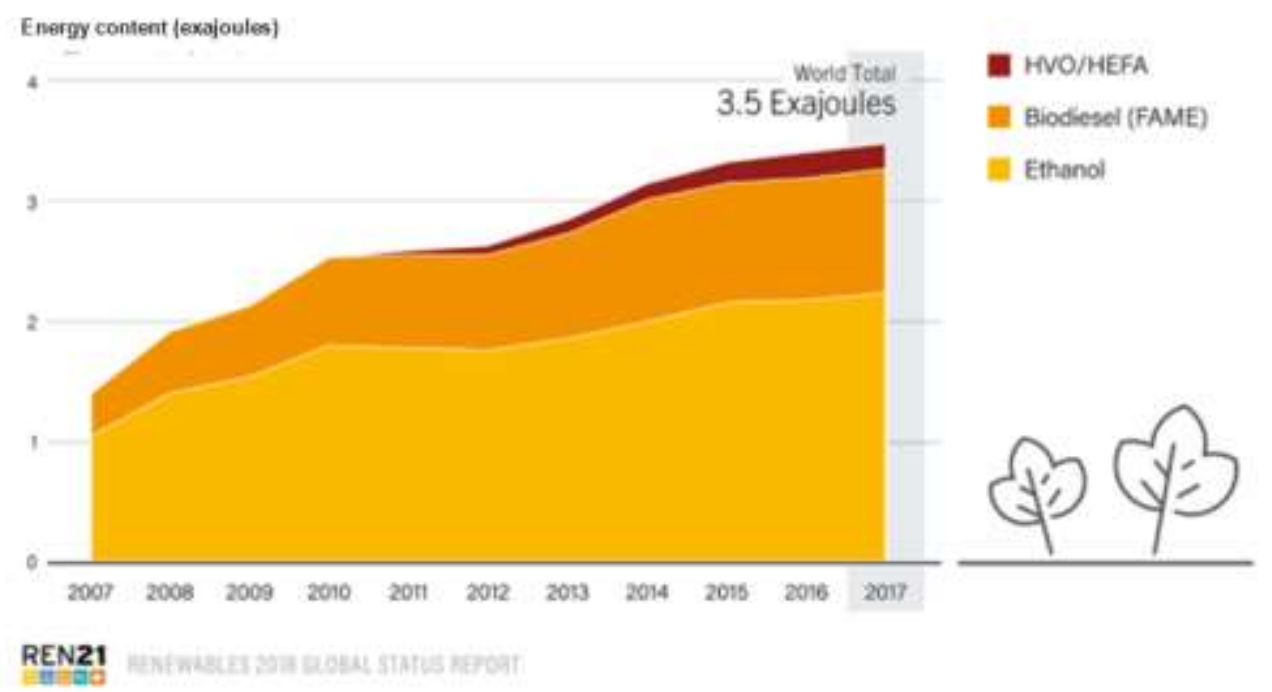

Fig.1. Global trends in biofuel production [1]

The use of biodiesel fuel as a substitute for diesel fuel has been widely promoted as part of a government program in the context of utilizing renewable energy. The utilization of biodiesel is done by increasing the percentage of biodiesel mixed with diesel fuel in accordance with the targets set. Countries that carry out the mandate for the use of biodiesel include Argentina (B10), Colombia (B10), Australia (B2), India (B5), Indonesia (B20), Malaysia (B10), and other countries [4]. Therefore, research on the development of biodiesel technology and the optimization of biodiesel supply chains are increasingly being carried out.

The flow of biomass from the land to its end use for producing biodiesel is called the biodiesel supply chain [5]. The biomass supply chains include different types of activities, such as cultivation, production, blending biodiesel with petroleum fuel, transporting, storing, and distributing to consumers. In this supply chain, at least three actors are involved, namely the biodiesel industry, the distributor of fuel oil, which distributes to consumers, and farmers of biodiesel raw materials. If there is government intervention, then there are four actors involved, including the government.

Biodiesel in the supply chain has become a very interesting topic to be investigated because of the times that require every country to look for alternative energy from renewable sources. Many researchers have produced models for biodiesel supply chains that address several issues, such as adding profits, adding to the supply chain costs, operating efficiency, or combining them as their goals. A systematic literature review that 
can point out exploration of the biodiesel supply chain, especially in Indonesia, is required to develop a better understanding of the biodiesel supply chain. This paper provides a literature review on the state of the art in biodiesel supply chain and research gaps in the biodiesel supply chain by classifying the previous literature into several categories. This review's objectives are i) an analysis of the state of the art of biodiesel supply chain research ii) a perspective from which this study suggest recommendations for future research that would expedite biodiesel usage and commercialization.

\section{Method}

To see the research trend in renewable energy study, this study conducted a systematic literature review. The first step is searching for articles from three Academic Databases, namely Scopus, Science Direct, and EBSCO. A literature review is done by looking at highly reputable papers. The keywords used in the literature review process are "biodiesel supply chain" in titles, and result in 286 papers. In the second step, elimination of duplicates articles was done and reduce articles to 266 . In the third step, analysis of articles titles and abstracts was performed. Based on the analysis, 135 of the 266 articles were selected. In the fourth step, in depth screening of full texts was done by reading abstract, introduction, methodology, conclusion and future research suggestion. The articles that did not contain the relevant topic were therefore excluded. The systematic process of literature review is shown by Figure 2 .

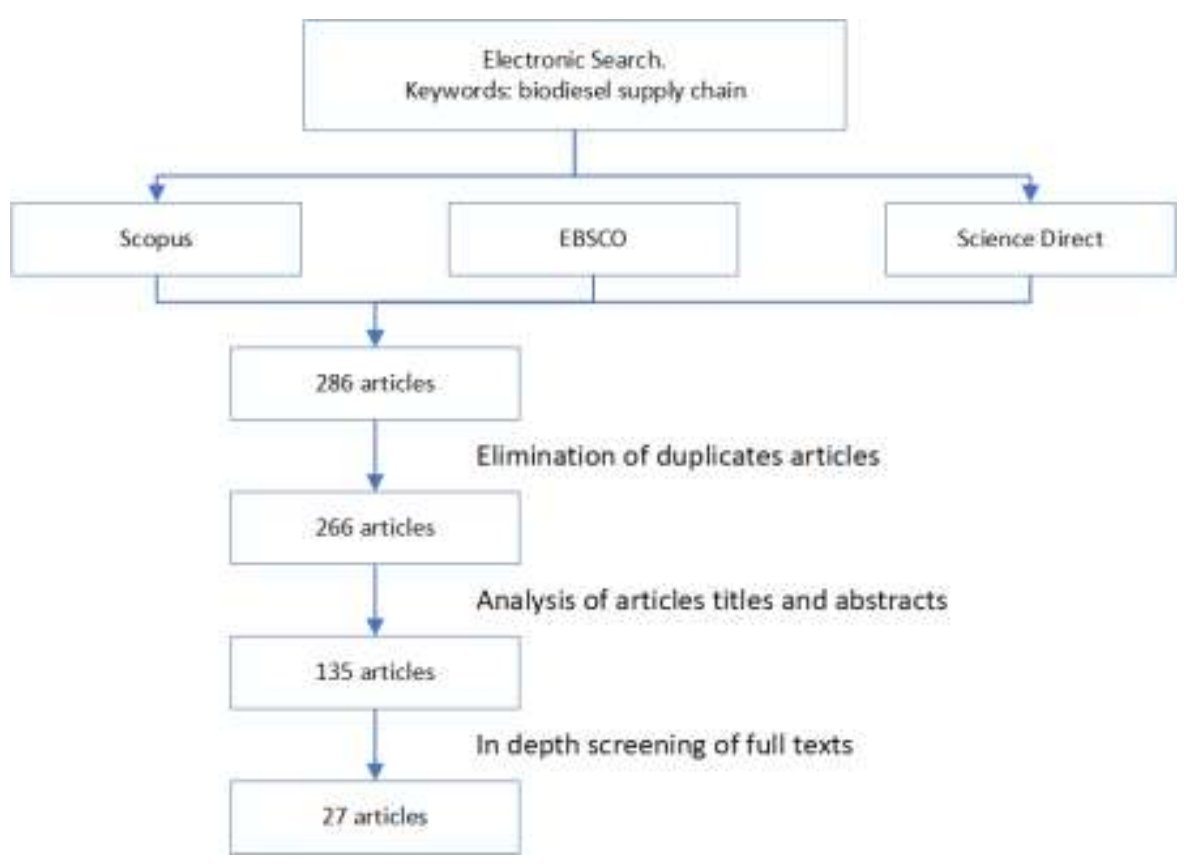

Fig.2. Systematic literature review

The classification framework for the biodiesel supply chain's literature review is described in six dimensions based on literature analysis. The six dimensions are resources, objectives, output decisions, addition issues, decision-making levels, and solution methodology. The classification can be seen in Figure 3 . 
The first dimensions describe the distinction between single resources and multiple biomass resources that are used for biodiesel fuel. The number of resources and the type of resources studied is very dependent on the geographical conditions and potential of the country being studied. The second objective describes the objectives of the paper on sustainable development. There are three types of objectives from literature i.e., objectives in the economic aspect, objectives in the social aspect, objectives in the environmental aspect, and objectives that are integrated between economic, social, and environmental aspects. The third dimensions describe the distinction between the type of decision to solve the problem. There are decisions in the plantation stage, production stage, blending stage, distribution stage, and consumer decision. The fourth dimension is additional issues added to the biodiesel supply chain. Through the literature study, three main issues that are important and widely discussed in the biodiesel supply chain, namely uncertainty, government intervention, and food security, are discussed.

Based on the analysis of literature works, the biodiesel supply chain also employed the planning decision level depending on the time horizon. Therefore the fifth dimension is based on the planning decision level, such as strategic, tactical, and operational planning level. The sixth dimension is used to review and classify the literature according to each biodiesel supply chain model's appropriate solution method. Amount two methods used to optimize and solve biodiesel supply chain problems that are simulation and optimization.

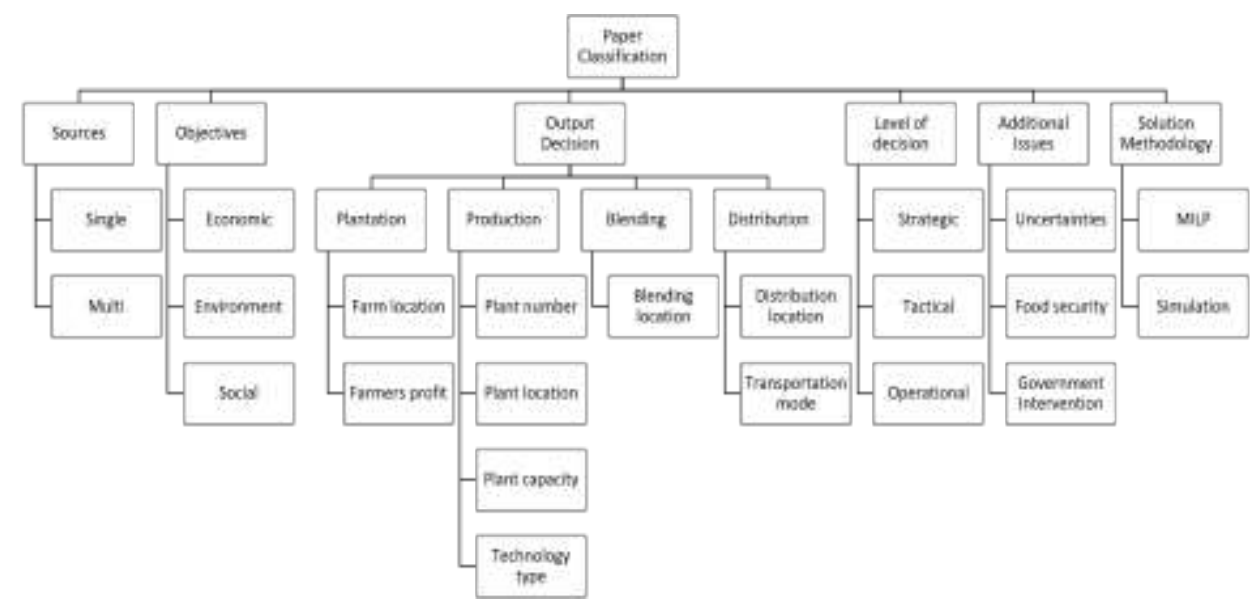

Fig.3. Paper classification on biodiesel supply chain

\section{Data analysis and result}

Based on the analysis of the literature, a classification framework for the literature review of the biofuel supply chain is done. The classification can be seen in Figure 3. This review of 27 paper [3, 6-31] gathered from science direct, EBSCO, and Scopus (Table 1). This 27 articles reviewed show the optimization of the biodiesel supply chain from the economic, social or environmental objective. 
Tabel 1. State of the art table

\begin{tabular}{|c|c|c|c|c|c|c|c|c|c|c|c|c|c|c|}
\hline \multirow[b]{2}{*}{ No } & \multirow[b]{2}{*}{ Author } & \multirow[b]{2}{*}{ Year } & \multicolumn{2}{|c|}{$\mathbf{R E}$} & \multicolumn{3}{|c|}{ Objectives } & \multicolumn{5}{|c|}{ Output decision } & \multirow{2}{*}{$\begin{array}{l}\text { Additio } \\
\text { nal } \\
\text { Issues }\end{array}$} & \multirow[t]{2}{*}{ Method } \\
\hline & & & $\mathbf{S}$ & $\mathbf{M}$ & 01 & $\mathbf{O 2}$ & $\mathbf{O 3}$ & $\begin{array}{l}\text { O } \\
\text { D1 }\end{array}$ & $\begin{array}{l}\text { O } \\
\text { D2 }\end{array}$ & $\begin{array}{l}\text { O } \\
\text { D3 }\end{array}$ & $\begin{array}{l}\text { O } \\
\text { D4 }\end{array}$ & $\begin{array}{l}\text { O } \\
\text { D5 }\end{array}$ & & \\
\hline 1 & [6] & 2011 & $\sqrt{ }$ & & $\sqrt{ }$ & & & & $\sqrt{ }$ & & $\sqrt{ }$ & & - & $\mathrm{O}$ \\
\hline 2 & [7] & 2012 & & $\sqrt{ }$ & $\sqrt{ }$ & & & $\sqrt{ }$ & & & $\sqrt{ }$ & & - & $\mathrm{O}$ \\
\hline 3 & [8] & 2011 & & $\sqrt{ }$ & $\sqrt{ }$ & & & & & & $\sqrt{ }$ & & - & $\mathrm{O}$ \\
\hline 4 & [3] & 2012 & & $\sqrt{ }$ & $\sqrt{ }$ & & & & $\sqrt{ }$ & & $\sqrt{ }$ & & - & $\mathrm{S}$ \\
\hline 5 & {$[9]$} & 2012 & & $\sqrt{ }$ & $\sqrt{ }$ & & & $\sqrt{ }$ & $\sqrt{ }$ & & $\sqrt{ }$ & & - & $\mathrm{O}$ \\
\hline 6 & {$[10]$} & 2013 & & $\sqrt{ }$ & $\sqrt{ }$ & & & & $\sqrt{ }$ & & $\sqrt{ }$ & $\sqrt{ }$ & - & $\mathrm{O}$ \\
\hline 7 & [11] & 2014 & $\sqrt{ }$ & & $\sqrt{ }$ & $\sqrt{ }$ & & & $\sqrt{ }$ & & $\sqrt{ }$ & $\sqrt{ }$ & - & $\mathrm{O}$ \\
\hline 8 & {$[12]$} & 2014 & $\sqrt{ }$ & & $\sqrt{ }$ & & & $\sqrt{ }$ & $\sqrt{ }$ & & $\sqrt{ }$ & $\sqrt{ }$ & - & $\mathrm{O}$ \\
\hline 9 & [13] & 2014 & & $\sqrt{ }$ & $\sqrt{ }$ & & & & $\sqrt{ }$ & & $\sqrt{ }$ & & - & $\mathrm{O}$ \\
\hline 10 & [14] & 2015 & & $\sqrt{ }$ & $\sqrt{ }$ & & & & $\sqrt{ }$ & & $\sqrt{ }$ & $\sqrt{ }$ & - & $\mathrm{O}$ \\
\hline 11 & [15] & 2015 & $\sqrt{ }$ & & $\sqrt{ }$ & $\sqrt{ }$ & & & $\sqrt{ }$ & & $\sqrt{ }$ & $\sqrt{ }$ & GI & \\
\hline 12 & [16] & 2016 & & & $\sqrt{ }$ & & & & $\sqrt{ }$ & & $\sqrt{ }$ & $\sqrt{ }$ & GI & S \\
\hline 13 & [17] & 2016 & & & $\checkmark$ & & & & $\sqrt{ }$ & & $\sqrt{ }$ & & - & $\mathrm{O}$ \\
\hline 14 & [18] & 2016 & & & $\sqrt{ }$ & & & & $\sqrt{ }$ & $\sqrt{ }$ & $\sqrt{ }$ & $\sqrt{ }$ & - & $\mathrm{O}$ \\
\hline 15 & [19] & 2016 & & & $\sqrt{ }$ & & & & $\sqrt{ }$ & & $\sqrt{ }$ & $\sqrt{ }$ & - & $\mathrm{O}$ \\
\hline 16 & [20] & 2017 & & $\sqrt{ }$ & $\checkmark$ & $\checkmark$ & & & & & $\sqrt{ }$ & $\sqrt{ }$ & - & $\mathrm{O}$ \\
\hline 17 & [21] & 2017 & & $\sqrt{ }$ & $\sqrt{ }$ & & & $\sqrt{ }$ & & & $\sqrt{ }$ & & GI & $\mathrm{O}$ \\
\hline 18 & [22] & 2017 & & & $\sqrt{ }$ & & & & $\sqrt{ }$ & & $\sqrt{ }$ & & - & $\mathrm{S}$ \\
\hline 19 & [23] & 2017 & & $\sqrt{ }$ & $\sqrt{ }$ & & & & $\sqrt{ }$ & & $\sqrt{ }$ & & - & $\mathrm{S}$ \\
\hline 20 & [24] & 2017 & $\checkmark$ & & $\sqrt{ }$ & & & & $\sqrt{ }$ & & $\sqrt{ }$ & $\sqrt{ }$ & - & S \\
\hline 21 & {$[25]$} & 2018 & $\checkmark$ & & $\sqrt{ }$ & & & $\sqrt{ }$ & $\sqrt{ }$ & & $\sqrt{ }$ & & - & $\mathrm{O}$ \\
\hline 22 & [26] & 2018 & $\sqrt{ }$ & & $\sqrt{ }$ & & & & $\sqrt{ }$ & & $\sqrt{ }$ & & UN & $\mathrm{O}$ \\
\hline 23 & [27] & 2018 & & $\sqrt{ }$ & $\sqrt{ }$ & & & $\sqrt{ }$ & & & $\sqrt{ }$ & & - & $\mathrm{O}$ \\
\hline 24 & [28] & 2018 & & $\sqrt{ }$ & $\sqrt{ }$ & & & $\sqrt{ }$ & $\sqrt{ }$ & & $\sqrt{ }$ & $\sqrt{ }$ & GI & $\mathrm{O}$ \\
\hline 25 & [29] & 2018 & & $\sqrt{ }$ & $\sqrt{ }$ & & & & $\sqrt{ }$ & & $\sqrt{ }$ & $\sqrt{ }$ & GI & $\mathrm{O}$ \\
\hline 26 & [30] & 2018 & $\sqrt{ }$ & & $\sqrt{ }$ & & & & $\sqrt{ }$ & & $\sqrt{ }$ & $\sqrt{ }$ & - & $\mathrm{O}$ \\
\hline 27 & {$[31]$} & 2018 & $\sqrt{ }$ & & $\sqrt{ }$ & $\sqrt{ }$ & & & & & $\sqrt{ }$ & $\sqrt{ }$ & - & $\mathrm{O}$ \\
\hline $\begin{array}{l}S: S \\
E: R \\
1: E \\
2: E \\
3: S\end{array}$ & $\begin{array}{l}\text { imulation } \\
\text { e sources } \\
\text { conomic } \\
\text { nvironment } \\
\text { ocial }\end{array}$ & & & $\begin{array}{l}\text { OD1 } \\
\text { OD2 } \\
\text { OD3 } \\
\text { OD4 } \\
\text { OD5 }\end{array}$ & $\begin{array}{l}\text { Planta } \\
\text { Produ } \\
\text { Blend } \\
\text { Distri } \\
\text { Trans }\end{array}$ & $\begin{array}{l}\text { ion } \\
\text { tion } \\
\text { ng } \\
\text { ution } \\
\text { ortatic }\end{array}$ & Issu & & $\begin{array}{l}\mathrm{S}: \mathrm{Si} \\
\mathrm{M}: \mathrm{N} \\
\mathrm{O}: \mathrm{O}\end{array}$ & $\begin{array}{l}\text { gle so } \\
\text { ulti so } \\
\text { timiz }\end{array}$ & $\begin{array}{l}\text { urce } \\
\text { urce } \\
\text { tion }\end{array}$ & & & \\
\hline
\end{tabular}

\subsection{Biofuel resources}

The first dimension describes the distinction between single resources and multi resources.

Biofuel can be determined as fuel from organic resources, including plants and animals. 
Biofuel has a specific characteristic that is renewable, whereas it can be produced by using raw material that can be grown or developed. There are a variety of biofuels potentially available, but the main biofuels being considered globally are biodiesel and bioethanol. However, first-generation biofuel technologies are often criticized for their implications on food prices and production. Then the biofuel supply chains using second-generation biofuel technologies is not compete with food security. These supply chains use crop residues, wood residues, or dedicated energy crops as feedstocks, thus avoid the potential impact on food markets.

Through a systematic literature review, it was found that based on the source of the raw material studied, research in biodiesel supply chain was categorized into two categories: research with one source of biomass raw materials and research with some sources of biomass feedstock. For research that falls into one biomass source category, the study will optimize the supply chain by optimizing each supply chain process. For research that falls into several biomass sources, optimization in the supply chain is carried out by selecting existing resources and then selecting biomass sources or combining several biomass sources to produce the maximum amount of biodiesel at minimum cost.

\subsection{Research objectives}

The research objectives in biodiesel supply chains are classified into three types: economic objectives, environmental objectives, and social objectives. For economic objectives, the study will try to meet the biodiesel quantity target produced at the minimum cost by optimizing the biodiesel supply chain. For economic objectives, [12] minimizes biodiesel supply chain's complete costs from feedstock supply to biodiesel delivery at the gas stations to determine the number, optimal location, size, and configurations of biodiesel production plants in Finland. Andersen et al. [7] minimizes supply chain cost by determining alternative locations and capacities for farms, biomass plantations, biodiesel production plants, and storage facilities, as well as distribution centers to internal and external markets [7]. Akram [9] minimize the total discounted costs of the supply chain involves the whole supply system's operating cost and the annualized capital costs. Reference [16] developed a stochastic mixed-integer programming model to make optimal decision include location of open biorefineries, amount of biomass transported to the biorefineries, amount of biodiesel production in biorefineries, amount of biodiesel transported to the markets, amount of Inventory and shortage of biodiesel in markets. Babazadeh [20] proposed model that is capable of determining the optimum numbers, locations, capacity of facilities, suitable transportation modes, and appropriate technology at bio-refinery, material flow, and production planning in different periods with a real case in Iran.

Social objectives are assessed from several things. But many studies have only evaluated social objectives by measuring job creation in the supply chain because it is easily quantified while other social measuring indicators are not easily measured. The social objective was quantified by the number of jobs generated. Leao et al. [6] determine the social aspect from calculating a minimum number of families to be hired in a selected production zone in a particular year or during the whole period. Quintero et al. [3] identified social aspects from the participation of associations of smallholders. Santibañez-Aguilar et al. [32] was quantified social aspects by the number of jobs generated. If concluded, all research on social aspects in the biodiesel supply chain is as far as the author's observation only assessed social objectives by measuring job creation.

Some studies carried out research with more than one goal or so-called multi-objective optimization. "Multi-objective optimization" is required when conflicting objectives are considered simultaneously. This often involves the tradeoff between economic, 
environmental, and social performances of the supply chain as well as the risks associated with design and operation.

\subsection{Output decision}

Through literature studies, the output of biodiesel supply chains is categorized into five major stages: the stages of the plantation, the stages of production, the stages of blending, the stages of distribution, and the consumer stages.

\subsubsection{Plantation}

The fundamental source of biofuel is the biomass feedstock, which is made of renewable biological materials. Production of biomass feedstocks includes all of the operations required for farmers to generate the feedstock, including plant breeding, planting, managing, and harvesting the crops from farmland, field, or forest.

\subsubsection{Production}

In production, the harvested biomass from regional farms is first collected and staged at the nearby shipping terminal or elevators and then subsequently shipped to a nearby biorefinery. The biomass conversion occurs at the biorefineries through bio-decomposition, fermentation, and distillation, yielding marketplace products. The problem of determining the best location for production zones and crushing units is to find an optimum point between the two extremes, seeking to balance logistical costs with investment costs. At one extreme, only one very large crushing unit would be built (minimum investment costs); at the other, a large number of very small units would be built (minimum logistical costs).

\subsubsection{Blending}

Several studies discuss the mixing of diesel and biodiesel. Andersen et al. [7] conducted research on the biodiesel supply chain's optimal design using the B10 policy scenario and determined the biodiesel mixing plant and transportation to be used. Hombach et al. [29] conducted a political policy scenario about the combination of the percentage of biodiesel mixed with diesel to combine ecological and social aspects with economic considerations.

\subsubsection{Distribution and transportation}

The final stage of a biofuel supply chain is the distribution and sales of fuels to endconsumers. Most of the biofuels in liquid form are shipped to retail outlets through existing fuel distribution systems to the transportation fuel market. These retail market outlets are typically gas stations owned by large oil corporates such as Pertamina in Indonesia, who also often own the biofuel blending facilities. High transportation cost, especially biodiesel transport, was a decisive factor in determining the numbers, capacities, and locations of new biodiesel plants. Neither increasing transportation cost nor decreasing plant construction cost changed the optimized supply chain configuration because the transportation cost was already high enough to dominate the supply chain optimization [30].

Supply chain optimization by paying attention to the transportation route is done by adjusting the area's spatial conditions being studied. For example, Jeong et al. [30] uses transportation routes despite the GIS network analysis by combining transportation modes. 
Andersen uses three modes of transportation (truck, rail, and ship) in the biodiesel supply chain, but does not use transportation routes (based only on the distance between the 2 points). Babazadeh et al. [21] uses two modes of transportation (truck and rail) for supply chain optimization.

In most studies, transportation costs or impacts were determined by assuming truck transportation and simulating the shortest distances over a road network. Transportation costs or impacts were determined by weighting the distances by feedstock and biofuel flows and unit-cost or impact factors. However, the shortest distances simulated over a singlemode do not guarantee economic routes. For example, Andersen et al. [7] uses three modes of transportation (truck, rail, and ship) in the biodiesel supply chain, but does not use transportation routes (based only on the distance between the two points). Babazadeh et al. [21] uses two modes of transportation (truck and rail) for supply chain optimization. To obtain a real transportation cost calculation, the optimization model with a geographical information system (GIS) must be applied. Several previous studies have done this. For example, Jeong et al. [30] uses transportation routes despite the GIS network analysis by combining transportation modes and uses the network analysis using OD cost matrix was used to determine minimum cost routes over regional multimodal transportation network, which is different from other studies in terms of analysis criteria, and multimodal network consideration

\subsection{Additional issues}

In this study, additional issues are categorized into three parts, namely food security, uncertainties, and government intervention.

\section{i. Government intervention}

Another critical factor in shaping the supply and demand of biofuel is government policy. To accelerate the development of the biofuel industry, the government is establishing various policies and imposing necessary instruments $[9,3,12,15]$. The major legislation promoting biodiesel is the government target to achieve BX blending in biodiesel. This policy aimed to stimulate the biodiesel industry by pressuring biofuel producers and distributors, to meet a biodiesel quota. Another instrument for promoting the biodiesel industry are subsidy [23] that granted to the farmer for growing rapeseed in German and incentives for diesel fuel mixture product and biodiesel in the form of product subsidy of IDR $1 \times 10^{6}$ per $\mathrm{kL}[24]$ in Indonesia.

Government subsidy to biodiesel production is another policy which decreases the biodiesel price [16]. The energy tax act specifies the biofuel policy defined an annual increase in biodiesel's tax rate [22]. Policies related to carbon was described by Maruffazaman et al. [33] and define carbon regulation into carbon cap, carbon tax, carbon cap and trade, and carbon offset.

\section{ii. Uncertainties}

Biofuel supply chains are subject to many uncertainties, which include, but are not limited to, seasonality and random yield of biomass, demand and price fluctuations, and production and logistical uncertainty. Other external factors, such as unpredictable regulatory policy changes and technological breakthroughs, also become challenges in biofuel supply chain management. Many biofuel supply chain models focus on the supply side of uncertainties associated with crop yield and seasonality. For example, Senna et al. [19] explain uncertainties in crop prices due to weather conditions, such as rainfall that impact seed 
production. Ghelichi et al. [26] describe uncertainty in biodiesel demand and raw material supply.

\section{iii. Food security}

The series of direct and indirect land-use changes have raised global concern. First, farmland competition between the food and biomass has led to the so-called 'food vs. energy' dilemma. Indeed, accompanying the rapid expansion of the biofuel industry, the food price worldwide has increased significantly. For example, the US's corn grain price increased from as low as USD 1.5 per bushel in 2000 to as high as USD 7.1 per bushel in 2013 (1 US bushel $=35.23907016688 \mathrm{~L}$ ), during the period in which the corn was the primary feedstock to bioethanol production [34]. Current research focuses on producing biodiesel from second-generation biofuel resources to avoid issues on food vs. fuel competition.

\subsection{Level of decisions}

There are three main decision-making processes in supply chain management: strategic, tactical, and operational decisions

\section{i. Strategic decisions in biofuel supply chain}

The strategic decisions are those decisions that influence over years and decades. Once a strategic decision is made, it is very unlikely to be altered in the short term. Strategic decisions in the biofuel supply chain include but are not limited to; i) selection of energy production technologies, ii) network configuration, iii) supply and demand contracts, and iv) ensuring sustainability, v) selection of plant location [35].

\section{ii. Tactical decision in the biodiesel supply chain}

Tactical decisions are medium-term decisions that involve sourcing decisions, production decisions, scheduling, transportation and logistical contracts, and planning process definition. Inventory decisions such as location, quality, and quantity of inventory are also considered. Decisions taken at the tactical decision level are planned to achieve and execute the strategic decisions [35].

Biomass sourcing decisions are crucial in the Biofuel Supply Chain (BSC) to minimize the geographical distance and increase accessibility to the raw material sources, among other factors. This ensures that the relatively isolated geographical allotment of significant biomass can raise researchers' interest in identifying the available biomass quantities over a region and subsequently proceeding with the selection of the optimal biomass sources.

\section{iii. Operational decisions in biofuel supply chain}

Operational decisions are short-term decisions that ensure the plants' continuous operation and other processes in the supply chain. These decisions are made daily or weekly, and sometimes several times to make sure that products are manufactured, moved, and sold in a timely and cost-effective manner. Some of the operational level decisions are detailed production scheduling, daily fleet management, and daily or weekly inventory review. The focus here is geared towards achieving the plan or framework set by the tactical supply chain decisions [35]. In the biofuel supply chain, this involves daily activities and planning such as transportation and logistics scheduling, demand forecasting, and review to meet the monthly targets. The plants' manufacturing planning and the detailed production and material requirements planning are usually reviewed at this decision level. 


\subsection{Solution methodology}

Since multiple conflicting objectives are often involved when optimizing biofuel supply chains' sustainability, several multi-objective optimization techniques can be applied, such as the epsilon-constraint method, goal programming method, etc. In the literature study, two standard methods were used that is mathematical modeling methods for optimization and simulation to see interactions that occur in the system. Many studies use the optimization method, as stated in Table 1. It is used to demonstrate the effects of maximizing the economic gain as well as minimizing the environmental impacts, with the help of appropriate presentation methods and optimization techniques. Integer variables are used in the model to carry out the selection of the geographic location(s) of the biomass and product storage and distribution facilities and the biofuel production plants.

\section{Discussions}

This review of 27 papers is gathered from science direct, EBSCO, and Scopus. Amount 27 articles reviewed show the biodiesel supply chain's optimization from the economic, social, or environmental objective. Although all of the articles point out the biodiesel supply chain, there are still some limitations of the previous research.

The first research gaps are transportation costs by determining infrastructure factors. In terms of objectives, economic optimization is the most objective type in biodiesel supply chain research. However, there are several limitations to the current literature. In transportation costs, many studies that calculate the cost of transportation only through transportation cost or impact are determined by transportation and simulating the shortest distances over a road network. Meanwhile, the shortest distance does not always guarantee an economic value that is smaller than another distance. Other factors, such as infrastructure, also determine transportation values. Research involving transportation by paying attention to minimum cost routes was only done by [30].

The second research gaps are uncertainties in biodiesel price. Due to the nature of the biofuel supply chain, many uncertainties exist. The uncertainties include but are not limited to: raw material supply and price uncertainties, finished goods demand and price uncertainties, pre-treatment uncertainties, production and yield uncertainties, and transportation uncertainties. To achieve optimal performance, the decisions of biofuel supply chain management should incorporate these uncertainties. Furthermore, biodiesel supply chain uncertainties will impact supply chains' performance and should be incorporated in many decision-making. Then [26] conducts research on biodiesel supply chains with uncertainty on supply and demand. Hombach et al. [17] see uncertainty in terms of demand uncertainty. Seeing that biodiesel prices are constantly changing, research with price uncertainty is important and is the second gap research of this study.

The third research gap is determining land use for food security in the biodiesel supply chain. The search for productive land for palm cultivation can lead to the conversion of natural ecosystems (tradeoff between cost and emissions) or the replacement of food crops (tradeoff between cost and food security). In these cases, there is a direct change in land use, which can be beneficial or harmful to the environment depending on whether the new crop absorbs more $\mathrm{CO}_{2}$. On the other hand, if the biofuel sources replace food crops and the latter move to natural areas such as unprotected forests, unmanaged pastures (scrubland), or extensive grazing areas (meadows), an indirect change of land use is generated. This replacement may lead to an increase in emissions (tradeoff between emissions and food security) [31]. This issue makes us must pay attention to land use for food security when thinking of biodiesel production from biomass. This is the third research gap in this research. 
The fourth research gaps are unique in the Indonesian case study. Many transportation problems were carried out in previous studies, and transportation used was limited to trucks and trains adapted to state conditions. Previous research has been carried out in continental Europe. However, the problem of transportation in the biodiesel supply chain in island countries that must participate in ships (barge) has never been studied. That became the fourth research gap from this study.

Since multiple conflicting objectives are often involved when optimizing biofuel supply chains' sustainability, several multi-objective optimization techniques can be applied, such as epsilon-constraint method, goal programming method, etc. In the literature study, two common methods were used that is mathematical modeling methods for optimization and simulation to see interactions that occur in the system.

\section{Conclusions and recommendations}

Amount 27 articles have been reviewed and classify based on six categories. The first category is based on the type of biodiesel resources: single or multi-resources. The second category is based on the objective of biodiesel supply chain: economic objective, environment objective and social objective. The third category is based on output decisions from each model. The fourth category is based on the level of decision: strategic, tactical, operational. The fifth category is based on additional issues founded: uncertainties, food security and government intervention. The sixth category is based on the solution methodology.

Future research on biodiesel supply chain should be focused on distribution type (location of plantation, production, blending, transportation, and flow amount in each stage) by determining infrastructure factors using a Geographical Information System (GIS). Besides it will optimize economic cost, the optimize distribution will minimize environmental impact by calculating GHG emissions in each stage and transportation used. Future research can also focus on determining land use to minimize conflict with food security and conduct research in island nations that require complicated modes of transportation, such as Indonesia.

\section{References}

1. J.L. Sawin, F. Sverrisson, J. Rutovitz, S. Dwyer, S. Teske, H.E. Murdock, et al. Renewables 2018-Global status report. A comprehensive annual overview of the state of renewable energy. Energy Planning, Policy and Economy. (2018).p.542 https://inis.iaea.org/search/search.aspx?orig_q=RN:49053208

2. Kumar, A., B. Sah, A.R. Singh, Y. Deng, X. He, P. Kumar, R.C. Bansal. Renew. Sust. Energ. Rev. 69,596-609(2017). https://doi.org/https://doi.org/10.1016/j.rser.2016.11.191

3. J.A. Quintero, E.R. Felix, L.E. Rincón, M. Crisspín, J.F. Baca, Y. Khwaja, et al. Energy Policy, 43:427-435(2012). https://doi.org/10.1016/j.enpol.2012.01.029

4. Lane, J. Biofuels Mandates Around the World 2019. 2019 [cited 20195 November]; Available from: https://www.biofuelsdigest.com/bdigest/2019/01/01/biofuelsmandates-around-the-world-2019/.

5. N.Z. Atashbar, N. Labadie, C. Prins. IFAC-PapersOnLine. 49,12:604-615(2016). https://doi.org/10.1016/j.ifacol.2016.07.742

6. R.R.d.C.C. Leão, S. Hamacher, F. Oliveira. Bioresour. Technol. 102,19:89588963(2011). https://doi.org/10.1016/j.biortech.2011.07.002 
7. F. Andersen, F. Iturmendi, S. Espinosa, M.S. Diaz. Comput. Chem. Eng. 47:170182(2012). https://doi.org/10.1016/j.compchemeng.2012.06.044

8. C. Papapostolou, E. Kondili, J.K. Kaldellis. Energy, 36,10:6019-6026(2011). https://doi.org/10.1016/j.energy.2011.08.013

9. A. Akram. Renew. Sust. Energ. Rev. 16,6:4196-4203(2012). https://doi.org/10.1016/j.rser.2012.03.023

10. B. Ivanov, B. Dimitrova, D. Dobrudzhaliev. J. Chem. Technol. Metall. 48,5:513523(2013). $\quad$ https://dl.uctm.edu/journal/node/j2013-5/13-Bojan\%20Ivanov-513523.pdf

11. M. Marufuzzaman, S.D. Ekşsioğlu. Transp. Sci. 48,4:555-574(2014). https://doi.org/10.1287/trsc.2013.0505

12. K. Natarajan, S. Leduc, P. Pelkonen, E. Tomppo, E. Dotzauer. Renew. Energ. 62,319330(2014). https://doi.org/10.1016/j.renene.2013.07.013

13. J.E. Santibañez-aguilar, G. Guillen-gosálbez, R. Morales-rodriguez, L. Jiménezesteller, A.J. Castro-montoya, J.M. Ponce-ortega. Bioenergy Res. 9,4:10531069(2016). https://doi.org/http://dx.doi.org/10.1007/s12155-016-9743-1

14. J. Ren, S. Tan, L. Yang, M.E. Goodsite, C. Pang, L. Dong. Energy Conversion and Management, 92:312-321(2015). https://doi.org/10.1016/j.enconman.2014.12.066

15. L.E. incón, M.J. Valencia, V. Hernández, L.G. Matallana, C.A. Cardona. Energy Econ. 47:154-167(2015). https://doi.org/10.1016/j.eneco.2014.10.018

16. A. Azadeh, H.V. Arani. Renew. Energy, 93:383-403(2016). https://doi.org/10.1016/j.renene.2016.02.070

17. L.E. Hombach, C. Cambero, T. Sowlati, G. Walther. J. Clean. Prod. 133:565575(2016). https://doi.org/10.1016/j.jclepro.2016.05.107

18. B. Ivanov, S. Stoyanov. Energy. 99:221-236(2016). https://doi.org/10.1016/j.energy.2016.01.038

19. P. Senna, D. Pinha, R. Ahluwalia, J.C. Guimarães, E. Severo, A. Reis. Production, 26,3:501-515(2016). https://doi.org/10.1590/0103-6513.200015

20. R. Babazadeh. Renew. Sust. Energ. Rev. 75:1089-1100(2017). https://doi.org/10.1016/j.rser.2016.11.088

21. R. Babazadeh, J. Razmi, M. Rabbanu, M.S. Pishvaee. J. Clean. Prod. 147:694707(2017). https://doi.org/10.1016/j.jclepro.2015.09.038

22. J.A. Moncada, M. Junginger, Z. Lukszo, A. Faaij, M. Weijnen. Appl. Energy, 195:370-381(2017). https://doi.org/10.1016/j.apenergy.2017.03.047

23. J.A. Moncada, Z. Lukszo, M. Junginger, A. Faaij, M. Weijnen. Appl. Energy, 185:895-915(2017). https://doi.org/10.1016/j.apenergy.2016.10.070

24. H. Wijaya, Y. Arkeman, E. Hambali. Agric. Eng. Int: CIGR J. 268-282(2017). http://cigrjournal.org/index.php/Ejounral/article/download/4554/2671

25. I.A. Emara, M. Gadalla, F. Ashour. Chem. Eng. Trans. 70:433-438(2018). https://doi.org/10.3303/CET1870073

26. Z. Ghelichi, M. Saidi-Mehrabad, M.S. Pishvaee. Energy, 156,1:661-687(2018). https://doi.org/10.1016/j.energy.2018.05.103

27. F. Ezzati, R. Babazadeh, A. Donyavi. Renew. Energy Focus, 26:81-92(2018). https://doi.org/10.1016/j.ref.2018.07.005

28. M. Leila, J. Whalen, J. Bergthorson. Energy, 156:181-195(2018). https://doi.org/10.1016/j.energy.2018.04.196

29. L.E. Hombach, C. Büsing, G. Walther. Eur. J. Oper. Res. 269,1:302-312(2018). https://doi.org/10.1016/j.ejor.2017.07.015

30. H. Jeong, H.L. Sieverding, J.J. Stone. Bioenergy Res. 12:229-240(2018).

https://doi.org/10.1007/s12155-018-9943-y 
31. J.A. Orjuela-Castro, J.A. Aranda-Pinilla, C.E. Moreno-Mantilla. Comput. Electron. Agric. 161:162-169(2018). https://doi.org/10.1016/j.compag.2018.03.009

32. J.E. Santibañez-Aguilar, J.B. González-Campos, J.M. Ponce-Ortega, M. SernaGonzález, M.M. El-Halwagi. J. Clean. Prod. 65:270-294(2014). https://doi.org/10.1016/j.jclepro.2013.08.004

33. M. Marufuzzaman, S.D. Eksioglu, Y. Huang. Comput. Oper. Res. 49:1-17(2014). https://doi.org/10.1016/j.cor.2014.03.010

34. M.K. Lim, Y. Ouyang. Springer. 143-162(2016).

http://publish.illinois.edu/mlim/files/2012/12/Lim_Ouyang_Biofuel-SCN_Final.pdf

35. I. Awudu, J. Zhang. Renewable and Sustainable Energy Reviews. 16,2:13591368(2012). https://doi.org/https://doi.org/10.1016/j.rser.2011.10.016 